[rao]

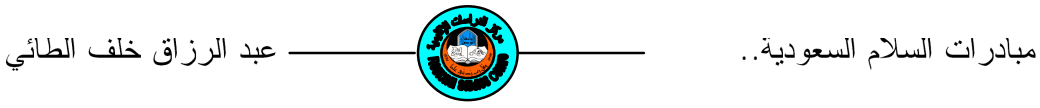

مبادرات السلام السعوديه تجاه الصراع العربي الإسرائيلي

\author{
عبد الرزاق خلف محمد الطائي \\ مدرس مساعد، قسم الدراسات السياسية والإستر اتيجية، \\ مركز الدراسات الإقليمية، جامعة الموصل
}

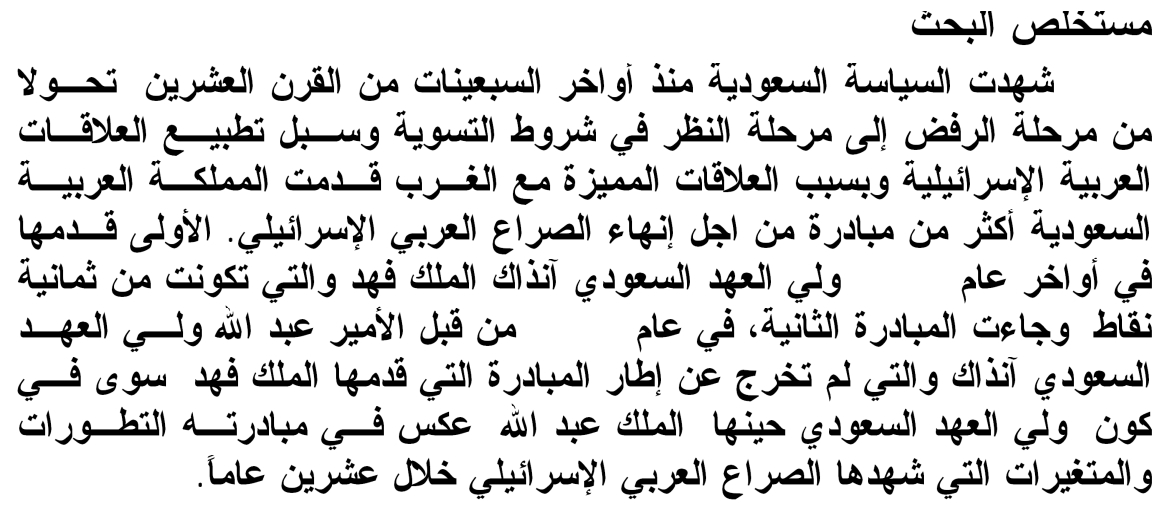

مotor

طرح عدد من مشاريع السلام العربية و الدولية من اجل تـسوية ســلمية

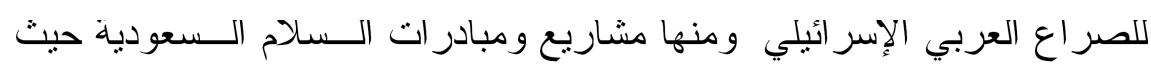

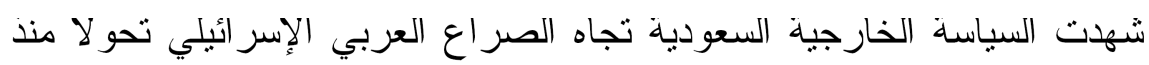

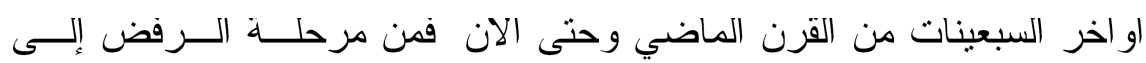

مرحلة النظر في شروط التسوية وسبل تطبيع العلاقات العربية الإسر ائيلية.

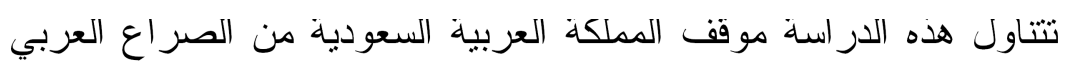

الإسر ائيلي و القضية الفلسطينية، ويناقش البحث دو افع ومحددات سياسة المملكة 
تجاه الصر اع العربي الإسر ائبلي، فضلا عن الوسائل التي اعتمدتها المملكة في

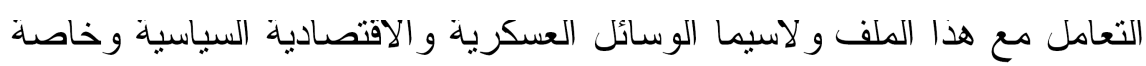

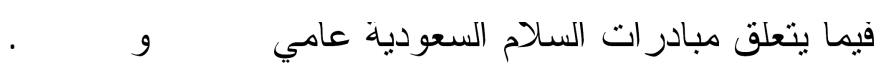

\section{اولا: تبدة تاريخيه}

كان لنشاة المملكة العربية السعودية الثاريخية و السياسية و الجغر افية اتــر

كبير على سياستها الخارجية ودو ائر اهتمامها التي تركز بالاساس على العالمين

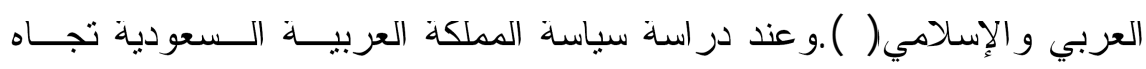

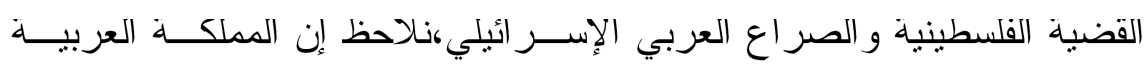
السعودية تحمل الغرب مسؤولية خلق النزاع العربي الإسر ائيلي، ومن واجـبـ الغرب ان يجد الحل الملائم له.

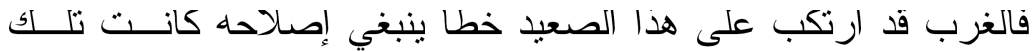

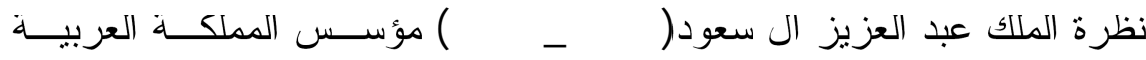

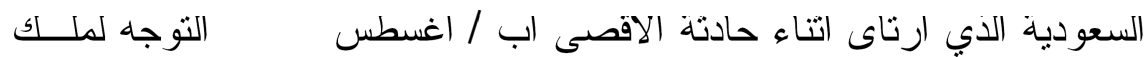
انكلتر ا من اجل لفت نظره حول النشاط الصهيوني (r).

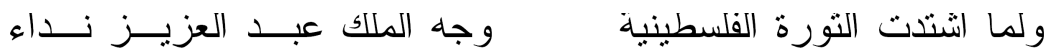
بالاشتر الك مع ملكي العر اق و اليمن و امبر شرق الاردن،إلى وقف التورة، وحين

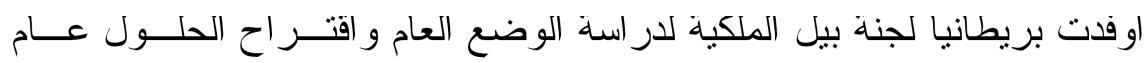

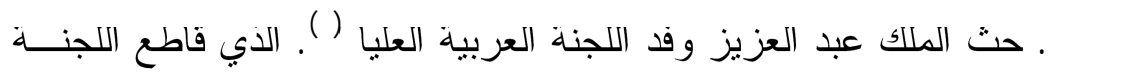

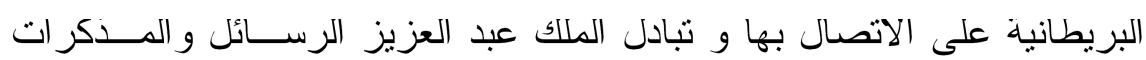

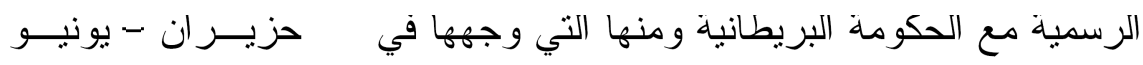

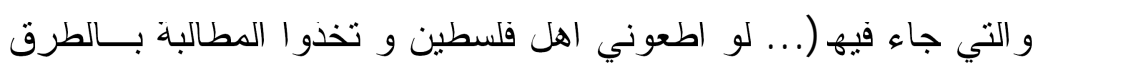


[rqv] عبد الرزاق خلف الطائي

السلمبة الوسيلة الوحيدة لمطالبهم مع بريطانية). وقد اوفد الملك عبد العزيز ابنه الامبر فيصل للمشاركة في مؤتمر لندن عام وسو 19 حول القضبية الفلـسطبنية. ودعا الفلسطينيين إلى الاشتر اك في المؤثمر ، وقد طالب الامبر فيــصل خ له المؤتمر بريطانبا وضع حد لتذفق المهاجرين اليهود (ع).

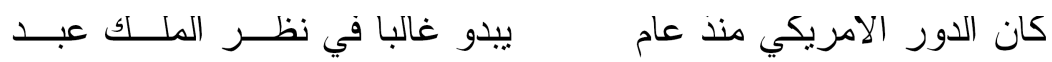
العزبز فيكتب للرئيس الامريكي روزفلت في ع/كانون التــاني '- بنــابر وسوا محذر منم خطورة الدعاية الصهيونبة (0) تم طلب منه اتتاء لقائه في 10 /لكانون الاول__ديسمبر 0ع 19 ممارسة بعض الضغوطات على الحكومـــة البربطانبــة لتخفف من ناييدها للحركة الصهيونية (7) الا ان فـي رســـالته إلــى الــرئيس الامريكي في 10/ايلول - ديسمبر 7ع 19 والتي اوضح فيها انه على الرغم من

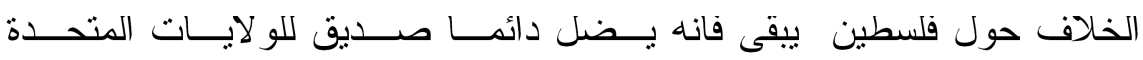
الامريكية.

وحين وصول ولي العهد سعود بن عبد العزيـز إلــى و اشــنطن فــي س I/كانون التاني - يناير VV I و ولدى اجتماعه مع الرئيس الامريكـي هـــاري

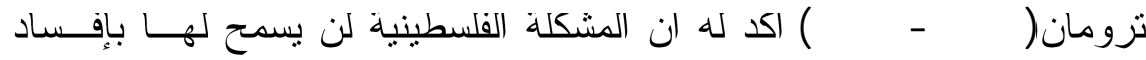

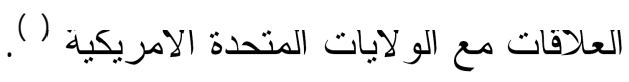

في 19 نشرين الثلاني - نوفمبر 19VV اصدرت الجمعية العامة للامـــ المتحدة القرار (رقم وناريخ) الخاص بثقسيم فلسطين - و عند انسحاب بريطانبـا

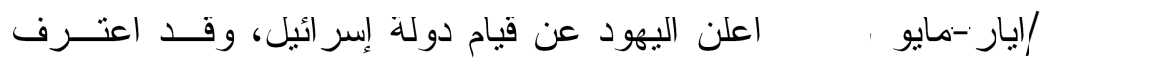
الرئيس الامريكي ثزومان على الفور بها.

رفضت المملكة العربية السعودية شـانها شان الاقطار العربية قد رفــضت

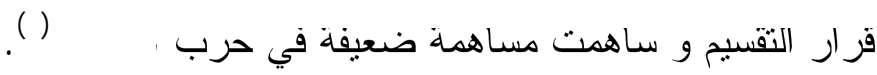


لم يختلف الملك سعود (190\% - 197ع) الذي خلف و الده الملــك عبــــ العزيز في سياسته عن و الده، فقد تجسد رد فعله على العدوان التلاتــي علـى لـى

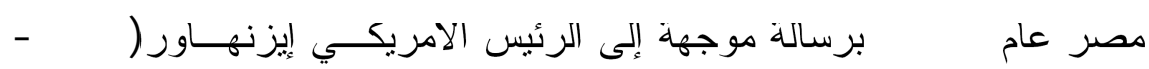

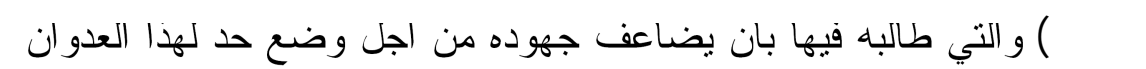

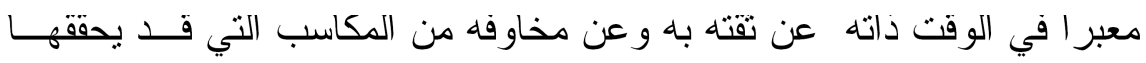

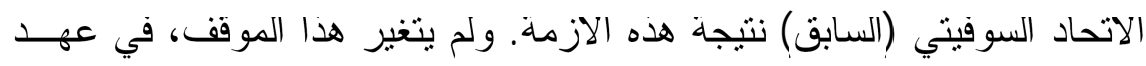

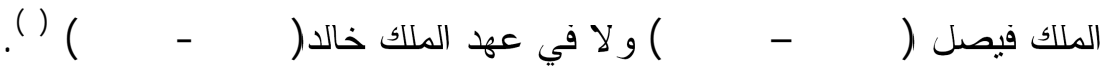
وقد غلب على موقف المملكة في التـــرك تجــاه الــصر اع العربــي الإسر ائيلي الطابع السياسي و انه ينوجب على العرب النحرك في إطار النظــام

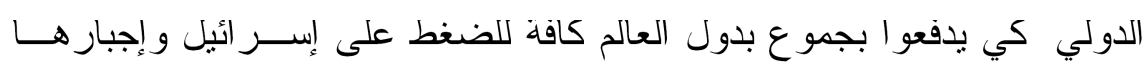

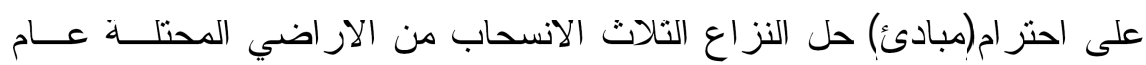

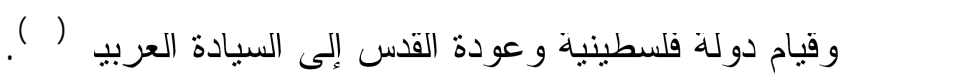
تانيا: محددات السياسه السعوديه تجاه الصراع العربي - الإسر ائيلي:

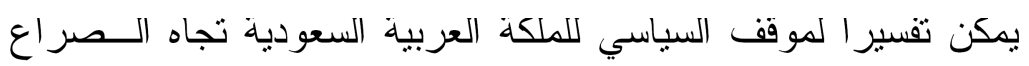
العربي - الإسر ائبلي عبر عدة محددات ولعل من اهمها: -

\section{| -المحدد الفكري (الإيديولوجيه الدينيه)}

للافع الديني دور كبير في مو اقف المملكة العربية السعودية من الصراع العربي الإسر ائبلي، وذلك لمكانة المملكة على صعيد العالم الإسلامي ووجــود مود الحرمين الثريفين في مكة المكرمة، والمدينة المنورة، فللدافع الديني و المؤسسة ولئ

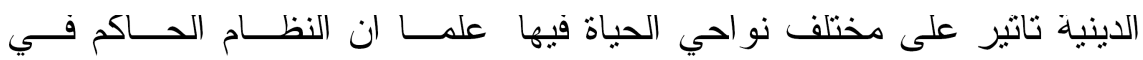


[rq9]

عبد الرزاق خلف الطائي
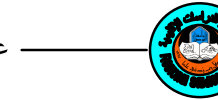

السعودية بعتبر هذه المؤسسة شريكا استر اتيجيا له وجز اء من النظـــام الحـــاكم.

وبالتالي فلا بد من اخذ ار اء هذه المؤسسة وموقفهــا مــن الــصراع العربــي

الإسر ائيلي (11) - (1)

\section{م -المحدات الامنيه والإستر اتيجيه:}

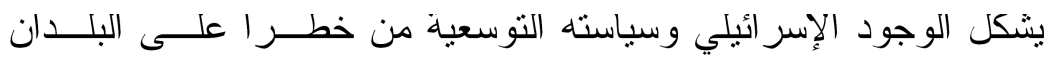

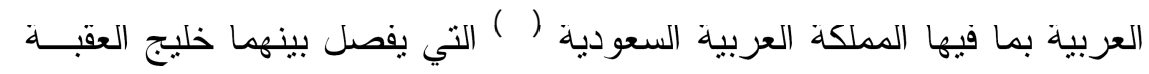
و الذي بحد من محاو لات القضابا التي بشكلها نطاق الصر اع العربي الإسر ائبلي

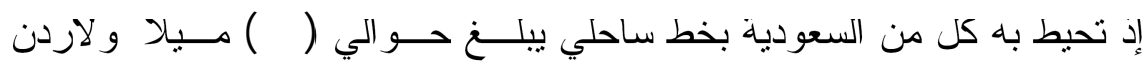
وخطها الساحلي خمسة امبال و "إسر ائيل" بخط ساحلي يصل إلى سبعة امبال نم

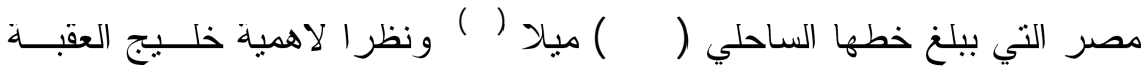
و الذي يقع في مدخله مضيق ثير ان الذي يكون المدخل المباشر للبحر الاحمــر بالنسبة لكل من الاردن، و إسر ائيل، نلاحظ السعودية تتازلت عن جزيرتي تبران وصنا فير السعوديتين عند مدخل الخليج لصالح مصر فـي شَـباط / فبر ايـر

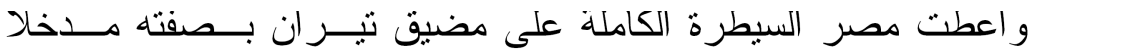
للخلبج، باعتبار إن السعودية و الاردن لم يكن في مقدور هما التــصدي الفعــال

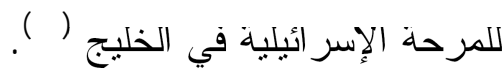

\section{r -المتغير ات الإعليميه و الدوليه:}

تذخل رغبة المملكة العربية السعودية في تكــوين دور إقليمــي ودولـي

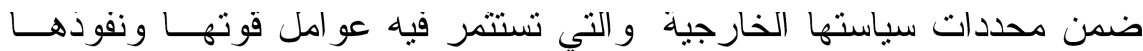

السياسي و الديني و الاقتصادي (10). 


\section{تالتا:الوسائل التي اعتمدتها المملكه تجاه الصراع العربي الإسرائيلي:}

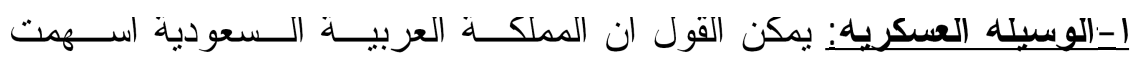

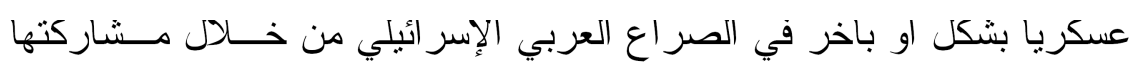

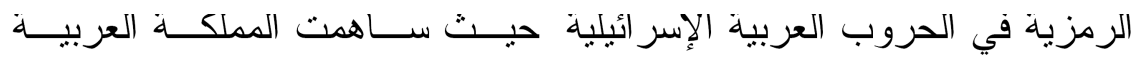

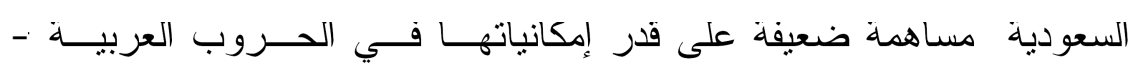

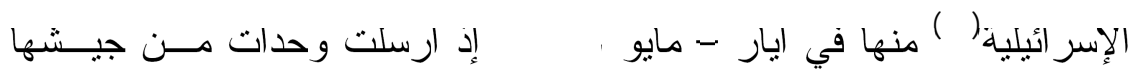
النظامي إلى مصر و امرت بوضعها تحت القيادة المصرية في صحر اء النقب

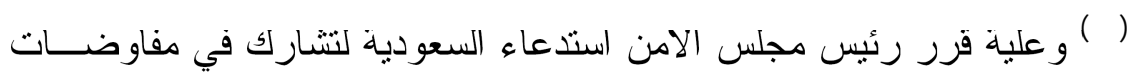
وقف إطلاق النار بوصفها دولة محاربة، كما دعبت السعودية للاشتر اك فـي

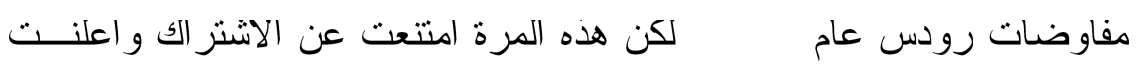

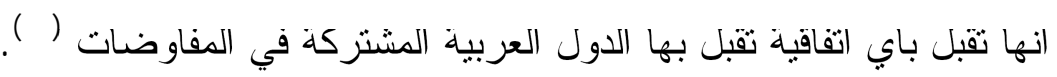

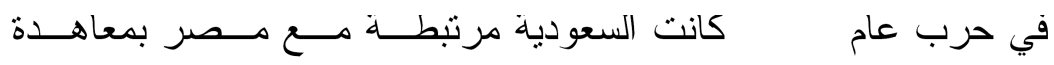

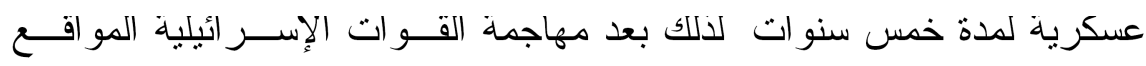
المصرية في سبناء، اعلنت الحكومة السعودية التعبئة العامة و على الرغم مـن

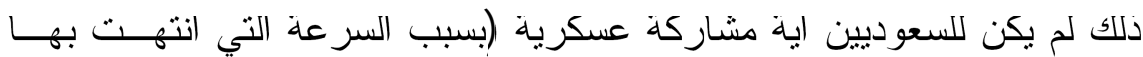
(الحرب).

وفي حرب عام 197V لم بكن قد نبقى شيء بذكر من الحلف المــصري

السعودي الذي كان سائدا في الخمسينيات. وكانت حرب اليمن في اوجهـ (19).

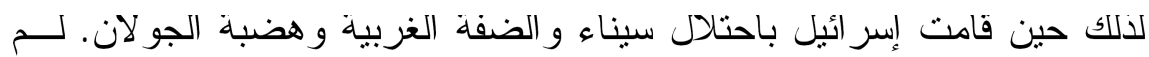
يكن من المتوقع ان تشارك المملكة العربية السعودية بالنزاع العسكري مباشرة.

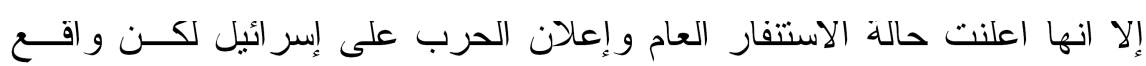
الحال ان السعودية لم تكن تسنطيع وثرغب بالقنال على الإطلاق (·r). 


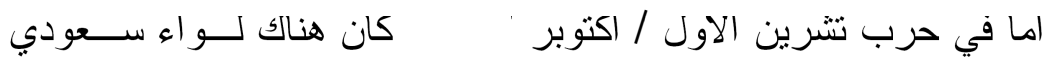

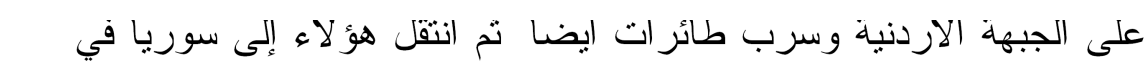

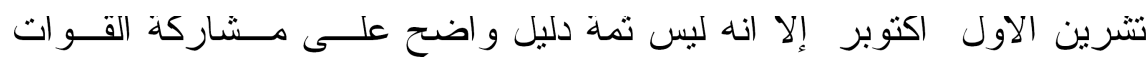

السعودية الفعلية في القتال (rال.

ب ــالوسيله الاقتصاديه:

كانت الوسيلة الاقتصادية من ابرز معالم السياسة السعودية تجاه الصر اع

العربي - الإسر ائيلي، و القضية الفلسطينية وقد اتخذت هذه الوسيلة عدة صــور ولعل من اهمها:

ا__دعم دول المو اجهة و المتضررة منذ عام 197Vا، ودعــم المقاومسـة

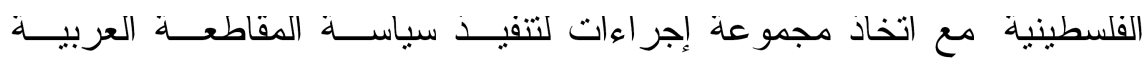

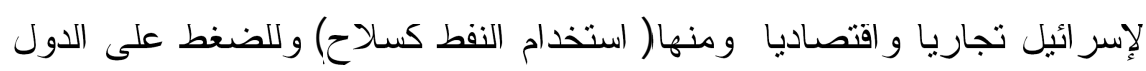

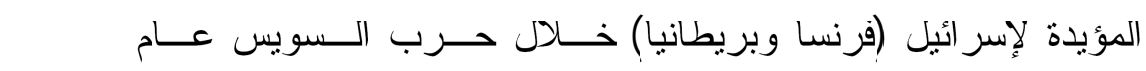

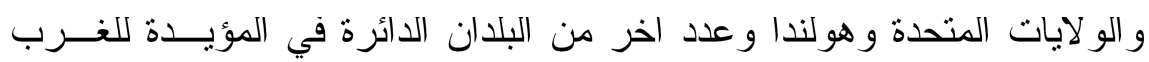

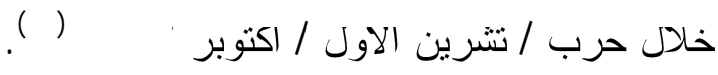

r_ قدمت السعودية تبرعات لدول المو اجهة و المتضررة منــذ مــؤتمر

القمة العربية المنعقد في الخرطوم عام 197V، كما النزمت السعودية في قــــة

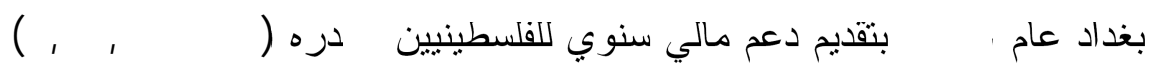

مليار وسبعة ونسعين مليون و تلاتمائة الف دو لار، ودلك لمدة عنر سنو ات (من

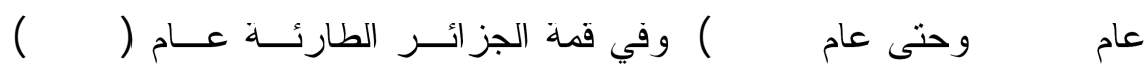
قررت السعودية تخصيص دعم شهري للانتفاضة الفلسطينية مقداره 7 مليــون

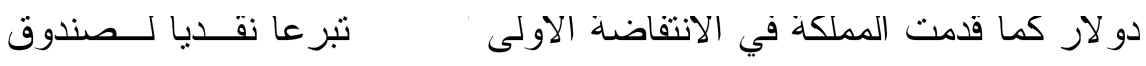

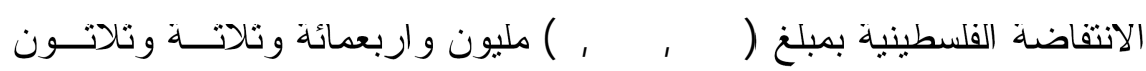


الف دو لار، وقدمت مبلغ (r) مليون دو لار للصليب الاحمر الدولي لثر اء ادوية ومعدات طبية و اغذية للفلسطبنيين (r/).

سـ_تعهدت المملكة بتمويل برنامج إنمائي عن طريق الصندوق السعودي

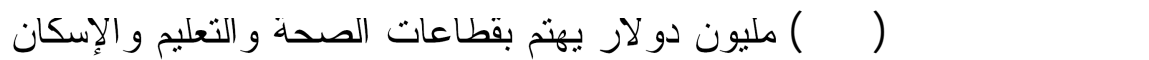

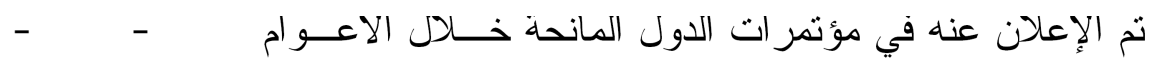
1999- 199V و على صعيد اخر اوقتت السعودية بكامل مساهماتها المقررة حسب قمة بيروت اذار / مارس r r . ب لدعم مبز انية السلطة الفلسطينية، وما اكدت عليه قمة شرم

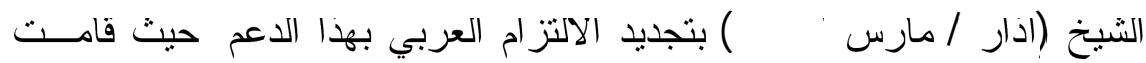

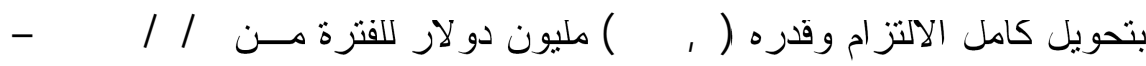

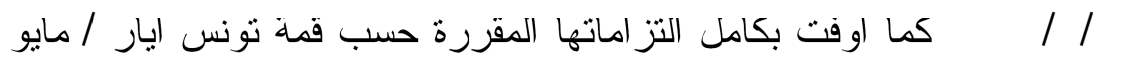

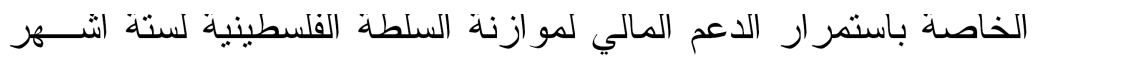

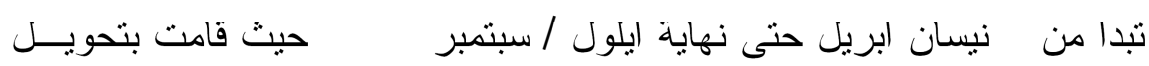

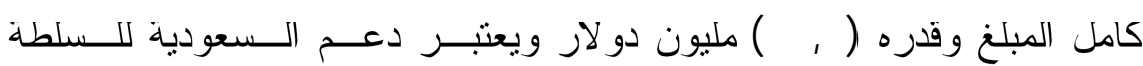

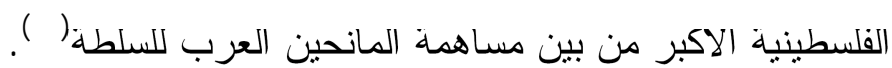

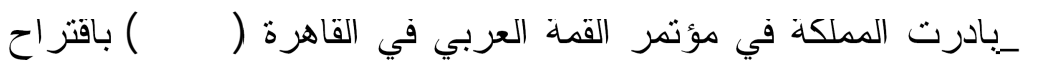
إنشاء صندوقين باسم صندوف (الاقصى) وصندوق (انتفاضة القدس) بر اســمال

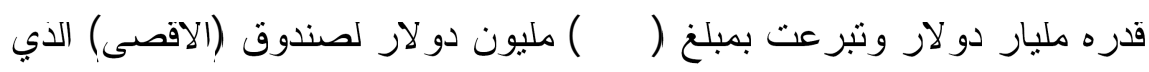

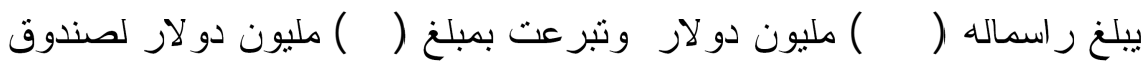

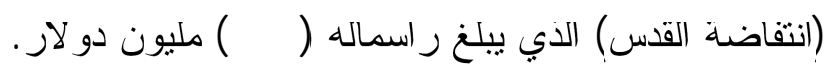
0_اهنمت السعودية بمشكلة اللاجئين الفلسطينيين حيث قدمت المساعدات رلهين الإنسانبية للاجئين الفلسطينيين مباشرة او عن طريــق الوكــالات و المنظمــات 
الدولية الني تعنى بشؤون اللاجئين مثل الانروا، منظمة اليونسكو، و الــصندوق العربي للإنماء الاقتصـادي و الاجتماعي و البنك الــدولي، و البنــك الإســـلامي، و المملكة ملتزمة في دفع حصنها المقررة لوكالة الامم المتحدة لإغاتة وتـششغيل

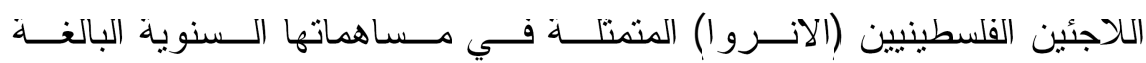

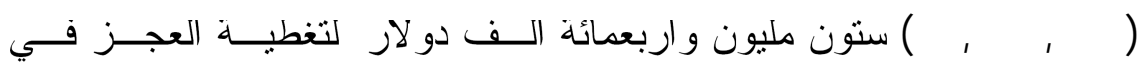
ميز انيتها وتتفيذ بر امجها الخاصة بالفلسطينيين كما خصصت المملكة للانــروا مبلغ (ए) مليون دو لار ضمن منحة الخاصة بالفلسطينيين كما خصصت المملكة

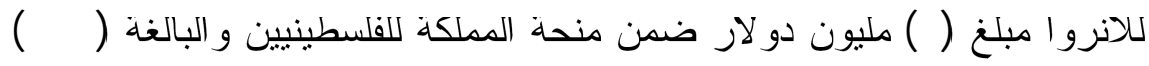

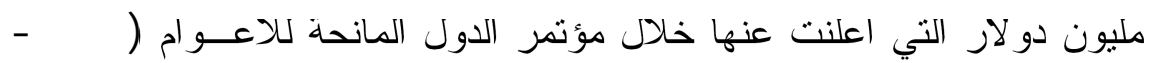
(ro) (1999-199V- 1997

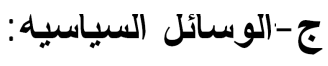
و اتخذت عدة صور لعل من اهمها:

(rา)

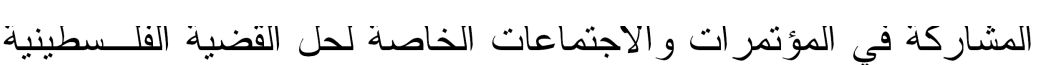
فضلا عن البيانات و الإدانات تجاه السياسة الإسر ائيلية (rV).

المبادرات السعوديه لحل الفضيه الفلسطينيه

\section{I -مشروع الامير قهر}

من خلال حديث ادلى به الامبر فهد بن عبدالعزيز ولي العهد الـسعودي

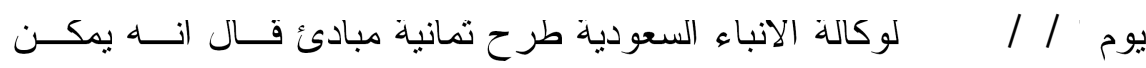

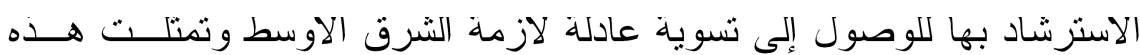

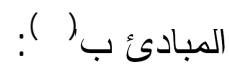


1 - انسحاب إسر ائبل من جميع الار اضي العربية التي احتلت عام $197 V$ بما

$$
\text { فيها القس العربية. }
$$

r - إز الذة المستعمر ات النتي اقامتها إسر ائيل على الار اضي العربيـــة المحتلــــة

$$
\text { بعد عام } 197 V .
$$

"ا - ضمان حرية العبادة وممارسة الشعائر الدينية لجميع الاديان في الامــاكن

$$
\text { المقدسة. }
$$

ع - تاكيد حق الشعب الفلسطيني في العودة إلى وطنه وتعويض من لا برغب

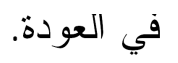

0 - تخضع الضفة الغربية وقطاع غزة لفترة انتقالية تحت إثر اف هيئة الامــــ

المتحدة ولمدة لا نزيد عن بضعة اشهر .

7 - قبام الدولة الفلسطينية المستقلة بعاصمتها القد.

$$
\text { - V }
$$

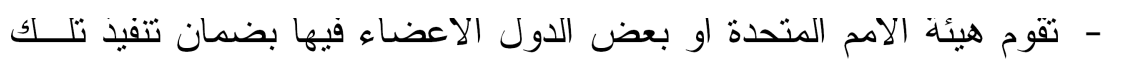

$$
\text { المبادئ. }
$$

وقد عرفت هذه المبادئ فيما بعد بـــششروع فهـ للسلام) و الــــي اعلــن

في مؤنمر القمة العربية الذي عقد في مدينة فاس المغربية عــام بو 199، لكـن

القمة لم تتبناه(ra).

\section{ردود الاهعال على مشروع هر للسلام}

تفاوتت ردود افعال الاقطار العربية على مبادرة فهر للسلام بين مؤيد لها

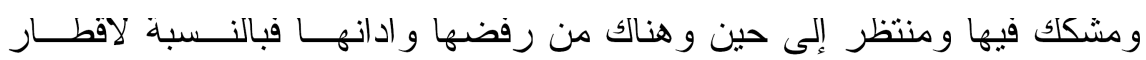

مجلس التعاون الخليجي و الذي بضم إلى جانب المملكة العربية السعودية، ك لـ ولل 
من الكويت وقطر و البحرين و الإمارات العربية المتحدة، وسلطنة عمان، فكانت من او ائل البلدان المرحبة بالمبادرة و اكدت مو افقتها علبها في القــــة الخليجيــة

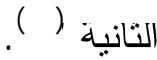

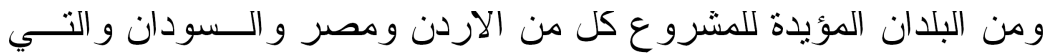

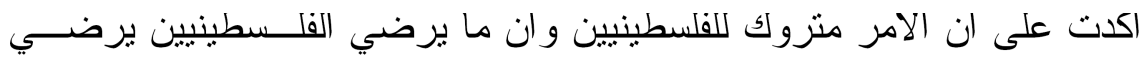

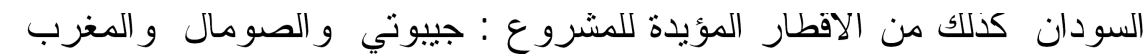
ونونس الني دعت إلى تعديل الفقرات التي نعنرض عليها باقي الاقطار العربية حتى يحصل المشروع على إجماع عربي (ابّ). اما سوريا و اليمن الجنوبي و الجز ائر وليبيا فقد رفضت المبادرة، في حين

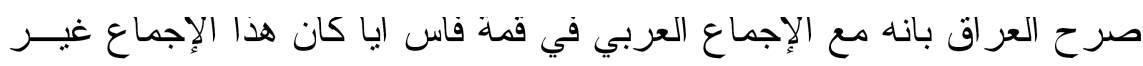

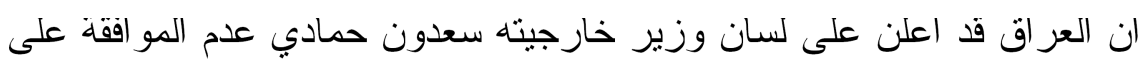

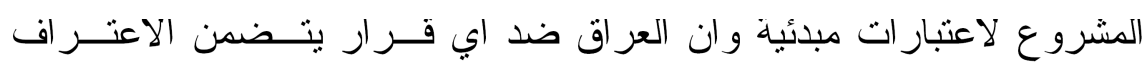
بإسر ائيل (بَ)

اما الموقف الفلسطيني فقد اعلن عنه فــاروق القــدومي رئسبس الإدارة السياسية لمنظمة التحرير الفلسطينية رفض المنظمة لاي قرار يعترف بإسر ائيل سو اء كان في مؤتمر وزر اء الخارجية العرب او في مؤنتر القمة العربية.

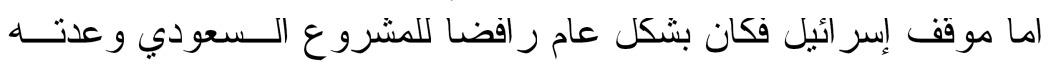

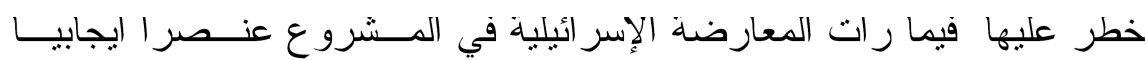

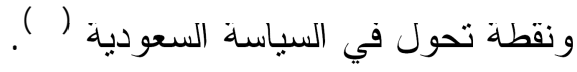

اما الولايات المتحدة الامريكية فلم تبد اهنماما يذكر بالمشروع ولكن بعد

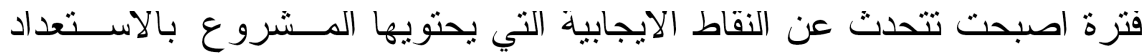

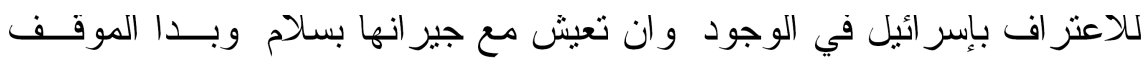

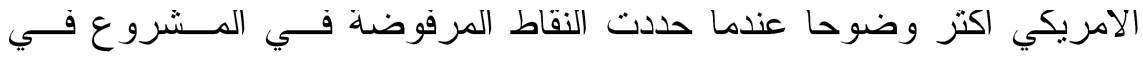
تصريحات لاحقة (عَ). 
وقالت مصادر فلسطينية ان الرئيس السوفيتي ليون بـــــــــي جينبـــ

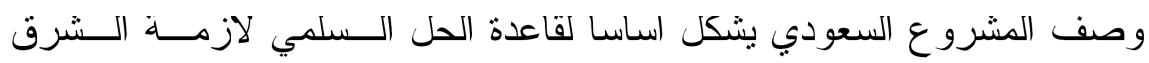

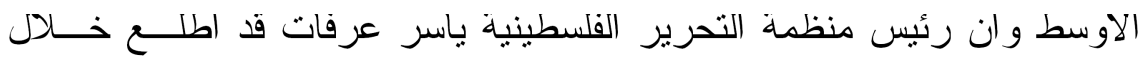

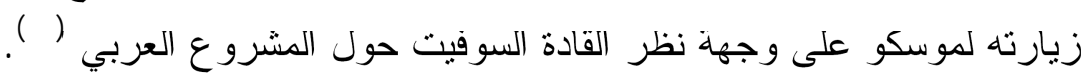

اما اوربا الغربية فقد رحبت بالمشروع ولكن على طريقتها الخاصة الني

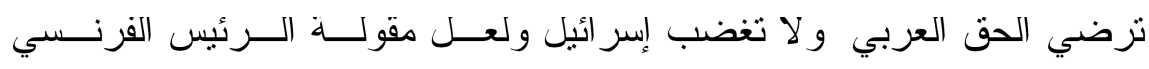

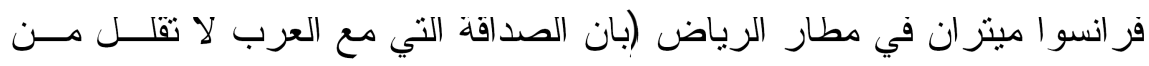

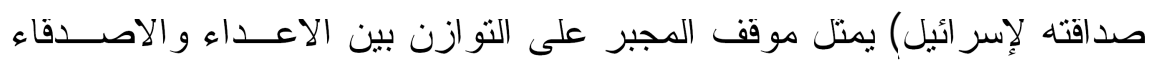

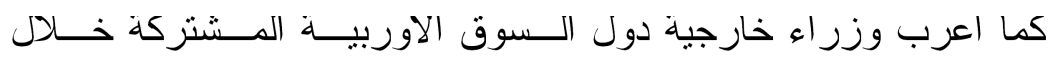

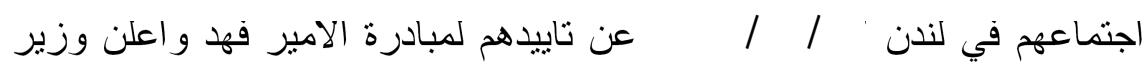

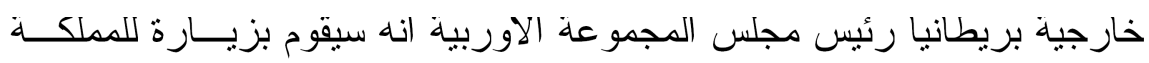

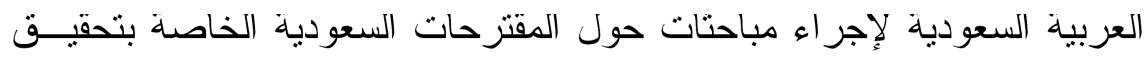

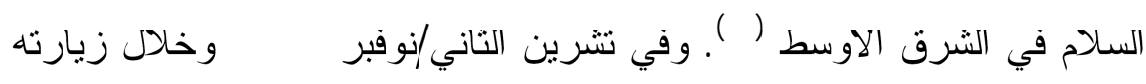

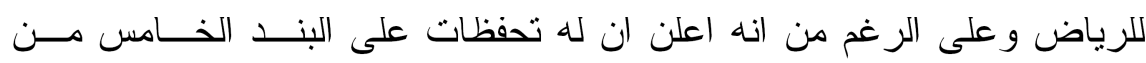

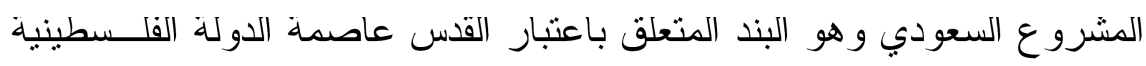

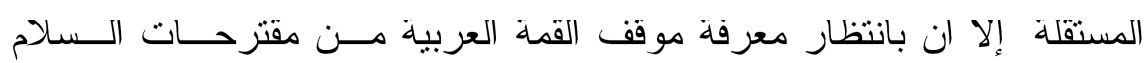
السعودية (ب^).

\section{م -مبادرة الملك عبد الله بن عبد العزيز}

ابتدات المبادرة السعودية التانية بحديث ادلى به ولي العهز السعودي فـي لئي

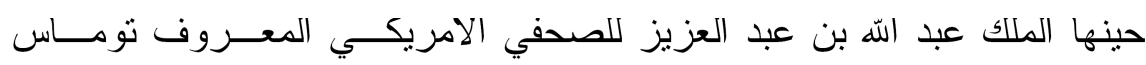

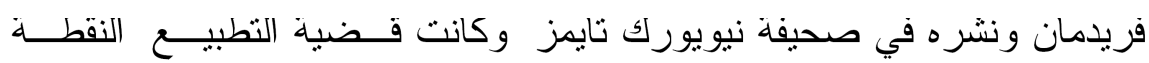


المتيرة للانتباه في المقابلة و التي اكدت اهمية وضرورة وضع حــــ للــصر اع العربي -الإسر ائيلي عبر مجموعة مطالب تقوم إسر ائيل بتحقبقها يتم على اترها بنطبيع عربي شامل معها.

وبالر غم من المعارضة الثدبدة لفكرة التطبيع، إلا ان مبادرة الملك عبــد

الله وجدت لها اذانا صـاغية في اغلب الدول العربية بـــليل ان مــؤثمر القــــة

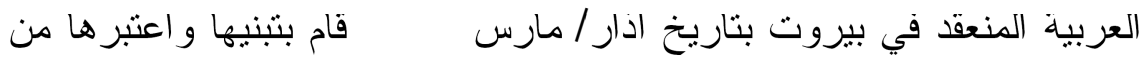

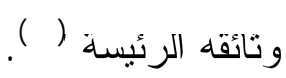

ونصت المبادرة: انسحاب إسر ائيل الكامل من جميع الار اضي العربية المحتلة

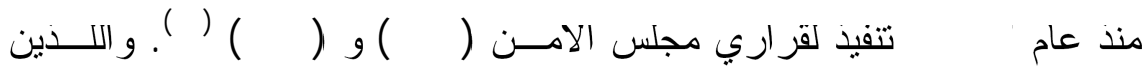
عززتهما قرار ات مؤتمر مدريد عام 1991 ومبدا الارض مقابل السلام، وقبول إسر ائيل قيام دولة فلسطينية مستقلة ذات سيادة وعاصمتها القــس الــشرقية، مقابل قيام الدولة العربية بإنشاء علاقات طبيعية مع إسر ائيل.

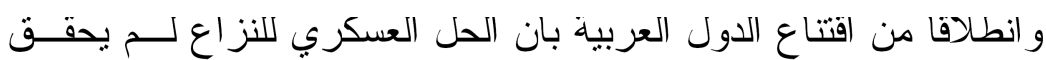
السلام او الامن لاي من الاطر اف.فقد طالبث بتحقيق النقاط الاتية لحل الصراع العربي الإسر ائيلي وهي: 1 - تعبد إسر ائبل النظر في سباساتها، و ان تجنح للسلم معلنة ان السلام العادل

$$
\text { هو خيار ها الاسنر اتيجي ايضا. }
$$

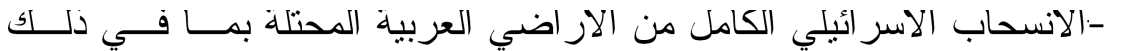
الجو لان السوري وحتى خط الرابع من حزيران / يونيو 197V، والار اضــي

$$
\text { التي ما ز الت محتلة في جنوب لبنان. }
$$

" - النوصل إلى حل عادل لمشكلة اللاجئين الفلسطينيين يتم الاتفاق وفقا لقرار

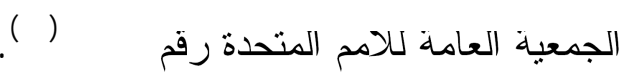


ع -قبول اسر ائيل قيام دولة فلسطينية مسـنقلة ذات ســيادة علــى الار اضــي الفلسطينية المحتلة منذ الر ابع من حزير ان بونيو $197 V$ في الضفة الغربيــة،

$$
\text { وقنطاع غزة وتكون عاصمنها القدس الشرقية. }
$$

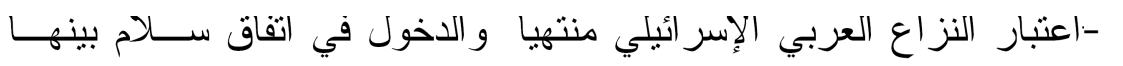

$$
\text { وبين إسر ائيل مع تحقيق الامن لجميع دول المنطقة. }
$$
r - إنشاء علاقات طبيعية مع إسر ائيل في إطار سلام شامل.

ب - -ضمن رفض كل اشكال التوطين الفلسطيني الذي بتلاعم و الوضع الخاص في البلدان العربية المضيفة. ع -يدعو المجلس حكومة إسر ائيل و الإسر ائيليين جميعا إلى قبول هذه المبــادرة المبينة اعلاه، حماية لفرض السلام وحقنا للاماء، بما بمكـن الــدول العربيـــة و إسر ائيل من العيش في سلام جنبا إلى جنب، ويوفر للاجيال القادمة مـستقبلا امن بسوده الرخاء و الاستقر ار . مائ. 0 -يدعو المجلس المجتمع الدولي بكل دوله ومنظماته إلى دعم هذه المبادرة. 7 -يطالب المجلس من رئاسته نشكيل لجنة خاصة من عدد من الدول الاعضاء

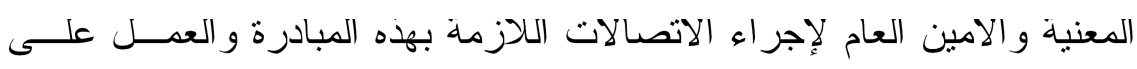
تاكيد دعمها على كافة المستويات وفي مقدمتها الامم المتحدة ومجلـس الامســن و الو لايات المتحدة و روسيا الاتحادية و الاتحاد الاوروبي (rع).

ردود الاهعال حول المبادرة:

لاقت مبادرة الامبر عبد الله انذاك ترحيبا واسعا من اغلب الدول العربية و الاجنبية، و ان كان هناك بعض التحفظات الني ظهرت علــى الــسطح بــادى 
الامر ، لكن سر عان ما اختقت وسارت الدول التي ابدت تحفظاتها فــي موكــبـ

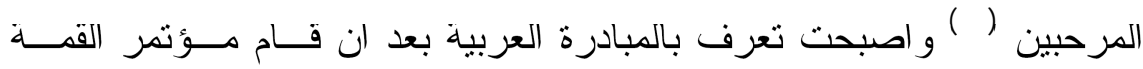

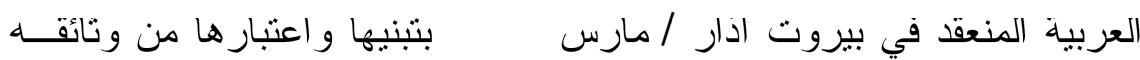

الرئبسة.

لقد ابدت إسر ائيل اول الأمر برودة و اضحة تجاه المبادرة بعد ان شعرت

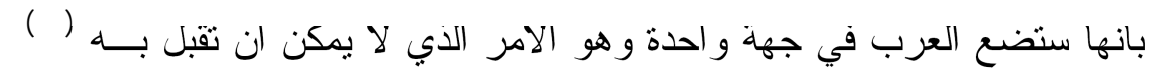

ولكن اللقاءات السرية الني نشرتها وسائل الإعلام الإسر ائيلية وقيل انها جمعت

بين الجانبين السعودي و الإسر ائيلي، و التي حاول فيها الطرف السعودي تغييـــر

وجهة نظر إسر ائيل تجاه مبادرة السلام السعودية الني القاها الملك عبد السّ (معان.

إلى شيء من هذا القبيل اشارت وزيرة الخارجية الإسر ائبلية تسيبي ليفني فـي

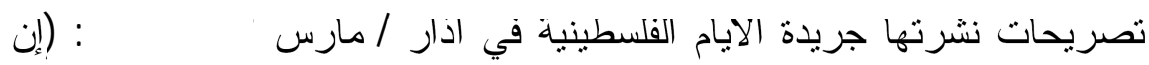

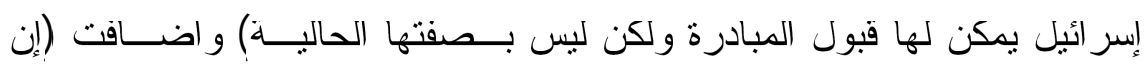
فقر ات جديدة دخلت على الخطة السعودية تثعلق بمصير اللاجئين الفلـسطينيين

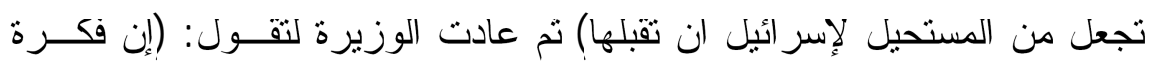

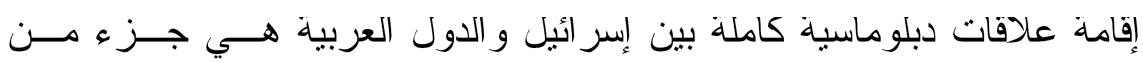
طموحنا، و انا اعتقد ان لنا هدف مشترك، و ان الخلافات بيننا تضمحل و المبادرة السعودية كانت ايجابية اول الامر ولكن منذ اضاف المنتشدون في مؤتمر قــــة

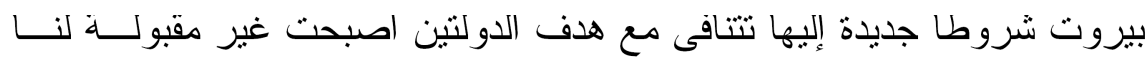

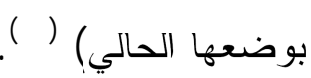

وفي التناني عشر من ادار / مارس V V. V عقد مجلس الوزراء الإسر ائيلي و الذي اكد على (انه يتحتم على إسرائيل النظر إلى المبادرة السعودية الاصلية الني كانت قد اسقطت حق العودة، بشكل ايجابي للغاية من 
قبل الحكومة، ويبدو ان إسر ائيل تشتبث بالنص الذي نشره الصحفي توماس

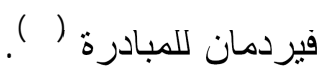

اما وزيرة الخارجية الامريكية كوندليز ا رايس فقد جددت دعوتها إلى

قادة الدول العربية إلى تعديل مبادرة السلام العربية، حتى بمكن ان تكون مقبولة

من الجانب الإسرائيلي. وشددت رايس على ان تعديل المبادرة العربية ليس مطلبا امريكيا، و إنما ضرورة للعرب على امل ان يكون ذلك بداية الطريق لقيام دولة فلسطينية جنبا إلى جنب مع إسر ائيل وفق ما تطرحه خطة خارطة الطريق

اما الموقف العربي من المطالب الإسر ائبلية و الامريكية المتعلقة بإســاط

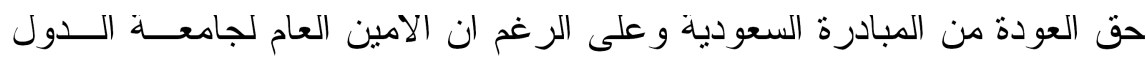
العربية عمرو موسى اكد بان المبادرة العربية لم تخضع للتعديل، إلا ان وزيـر

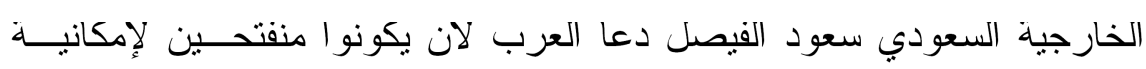

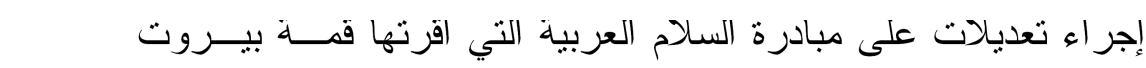

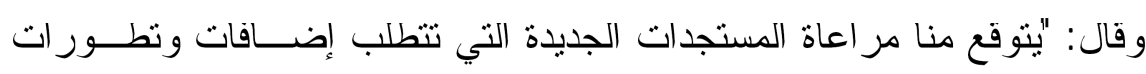

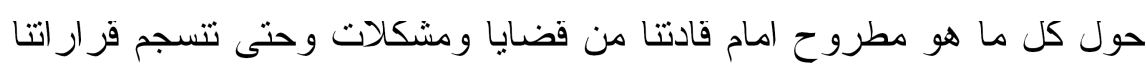

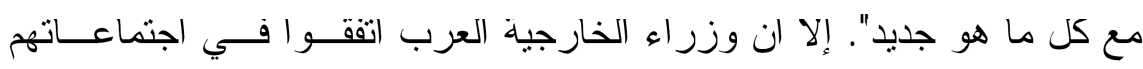
التمهيدية لقمة الرياض على تفعيل المبادرة دون إجر اء اي تعديل عليها (وع).

الخاتمه

لقد مر الصر اع العربي الإسر ائيلي بالعديد من المراحـلـل بــين العهــل

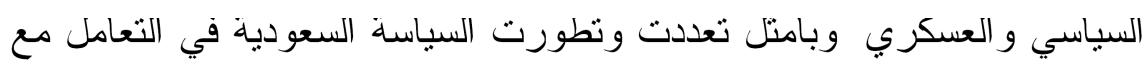
المتغبر ات السباسية بما في ذلك السلام مع إسر ائيل. 
إذ شهدت السياسة السعودية منذ او اخر السبعينات من القرن العـشرين،

تحولا من مرحلة الرفض إلى مرحلة النظر في شروط التسوية وســبل تطبيــع العلاقات العربية الإسر ائبلية وبسبب العلاقات الممبزة مع الغرب قدمت المملكة العربية السعودية اكثر من مبادرة من اجل إنهاء الصر اع العربي الإســر ائيلي. الاولى قدمها في اواخر عام 1911 ولي العهد السعودي انذاك الملك فهد والتي تكونت من تمانبة نقاط، وجاءت المبادرة الثانبة، في عام r . . r من قبل الامبر عبد الهّ ولي العهد السعودي انذاك و التي لم تخرج عن إطار المبادرة التي قدمها الملك فهذ، سوى في كون، ولي العهد السعودي حينها، الملك عبد الله، عكس في مبادرته التطور ات و المتغير ات التي شهـها الصراع العربــي الإســر ائيلي خلال عشرين عامـا.

إن العقبة الرئيسة التي واجهت مبادرة الملك عبد الهّ هي فــي مو اصـلـة

إسر ائيل إعطاء مو اقف منباينة من المبادرة و الثهرب من استحقاقاتها و الاعتقــاد انها لبست مضطرة إلى دفع ثمن للتطبيع مع العرب في ظل اخــنالال مــو ازين القوى بالمنطقة، و اعتماد سباسة المماطلة و التسويف ومحاولة احتو اء المو اقـف بإبداء مرونة شكلية تجاه المبادرة مع محاولة إفر اغها من مضمونها، اي البـــد بالتطبيع قبل القيام باية خطو ات ملموسة تتمنل بالانسحاب من الار اضي العربية و الفلسطينية المحتلة كما اشّارت لها المبادرة. 


\title{
Saudi Peace Initiatives Towards Arab-Israeli Conflict
}

\author{
Abdalrazaq kh. Mohammed \\ Assistant Lecturer/ Department Of Historical \& Cultural Studies, \\ Regional Studies Center, Mosul Univesity
}

\begin{abstract}
The Saudi policy towards Arab-Israeli conflict since the end of 1970,s had shifted from refusal stage to the stage of taking up settlement conditions and the way of normalization of Arab-Israeli relations.Due to its excellent relations with the west, Saudi Arabia made more than one peace initiative to put an end to the conflict. the first was 1982 by King Fahad who was the crown prince at that time, which consisted eight points. the second initiative was by King Abdullah who was the crown prince in that period. the only difference between the two initiatives is that King Abdullah initiative reflected the development and variables in Arab- Israeli conflict within twenty years
\end{abstract}




$$
\text { المصنادر }
$$

http://www.ksa.edu.sa/kfa-webite/source/84.htm

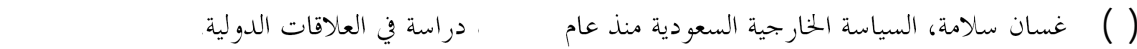

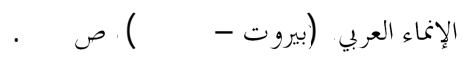

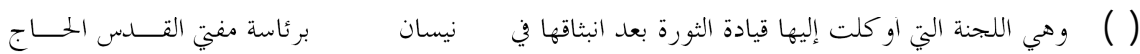

محمد أمين الحسيين والتي ضمت تحت لوائها معظم المنظمات والاحزاب الفلسطينية، اما اعضاء اللجنة الاخرون

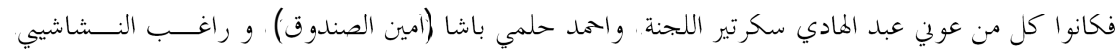

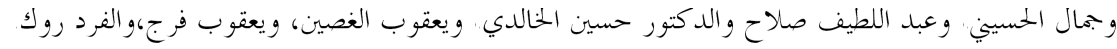

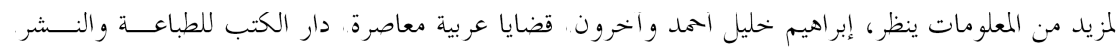

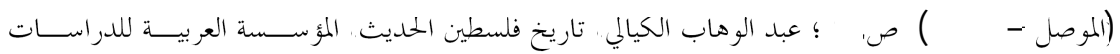

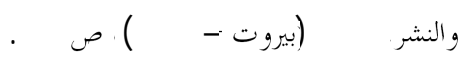

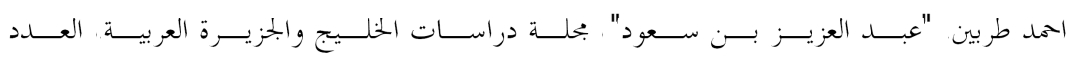

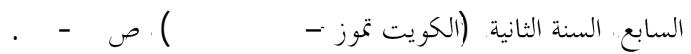

(0) (1) ملافة، مصدر سلق، ص.0ع.

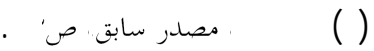

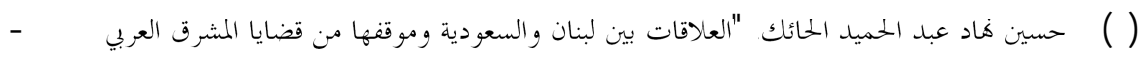

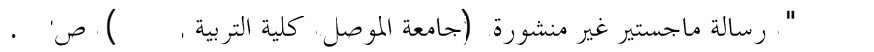

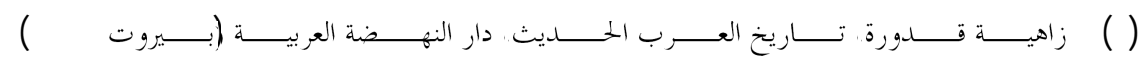

صT

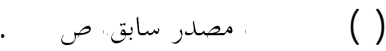

$$
\begin{aligned}
& \text { ( (1) المصدر نفسه، ص } 000 .
\end{aligned}
$$

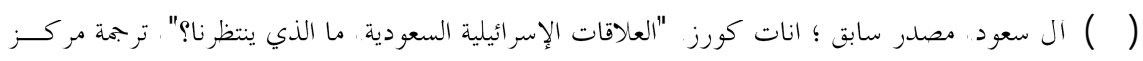

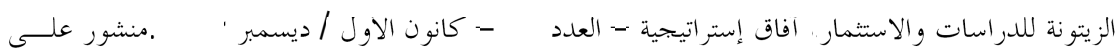

http://www.alzaytoouna.net/?c-593\&a= 54715

$$
\text { . (IT) }
$$

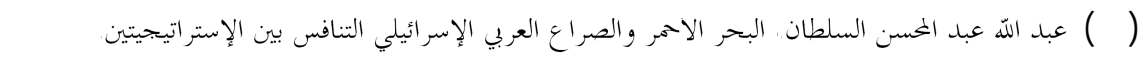

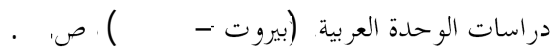




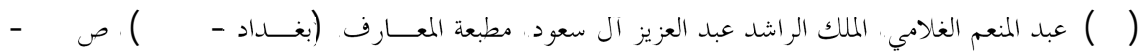

$$
\text { (1) }
$$

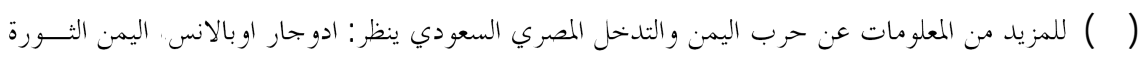

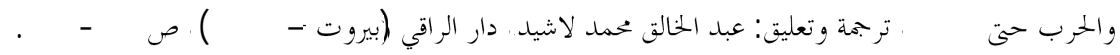

$$
\text { (Y.) }
$$

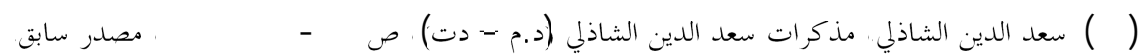

مو مق المملكة العربية السعودية بحث على موقع وزارة الخار جية للمملكة العربية السعودية على الموقع: http://www.mofa.gov/Detail.asp?

$$
\begin{aligned}
& \text { (Y ) المصدر نفسه. }
\end{aligned}
$$

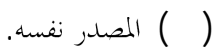

$$
\begin{aligned}
& \text { (Y) (Y) (Y) (K) المصدر نفسه. }
\end{aligned}
$$

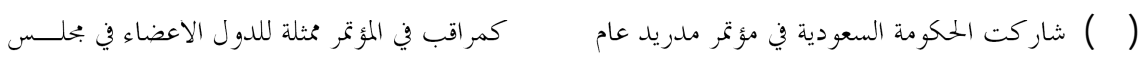

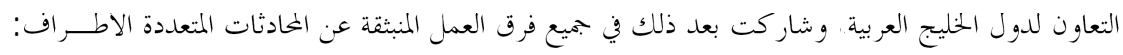

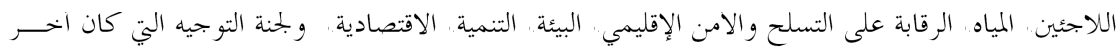

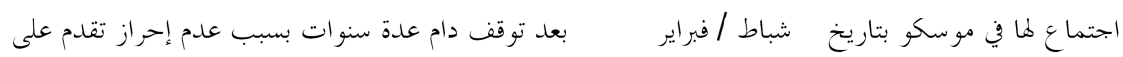

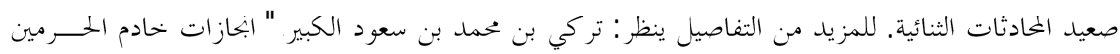

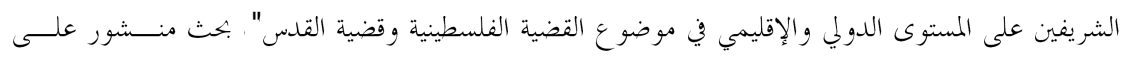

http://www.ksa.edu.sa/kfswebsite/searchresult?

$$
\text { الموقع: }
$$

؛و كذلك بمموعة باحثين، مدخل إلى القضية الفلسطينية، ترير جو اد الحمد، مر كز دراسات الشرق الاوسط، طالج،

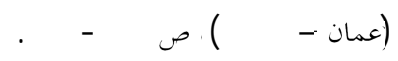

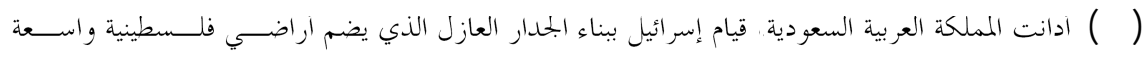

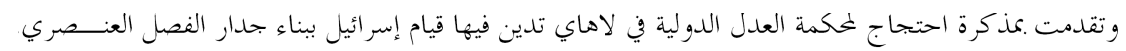

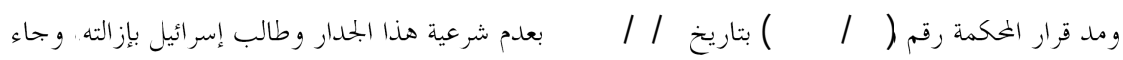


[rio]

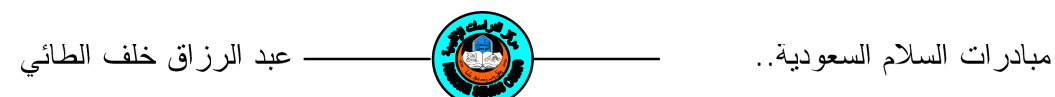

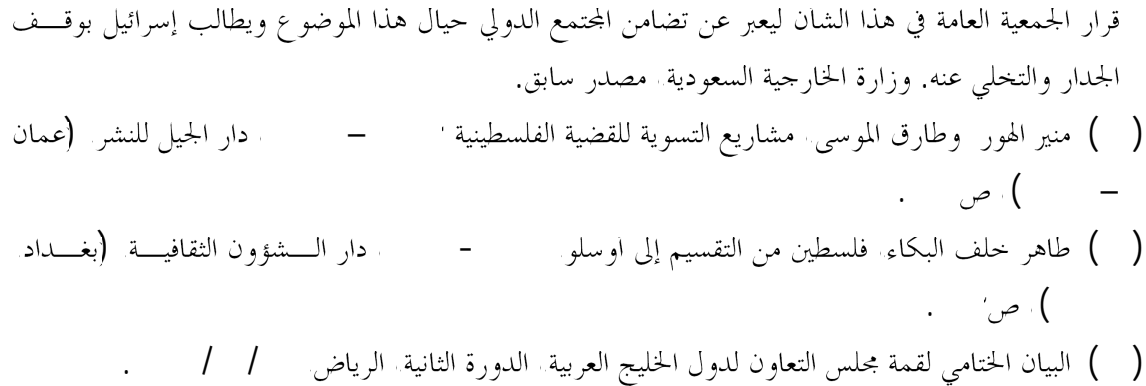
http://www.kuna.net.kw/gce/index.asp

(آ) خمد جاسم محمد وظمياء كاظم الكاظمي، مشروع فهد للسلام في الشرق الاوسط في الدوريات العربية

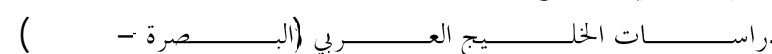

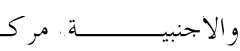
. TTA - MTVD

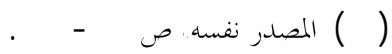

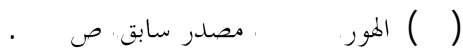

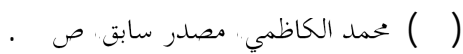

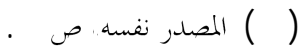

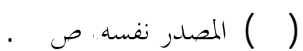

(rV)

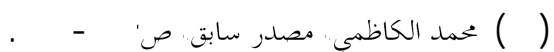

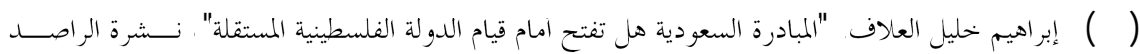

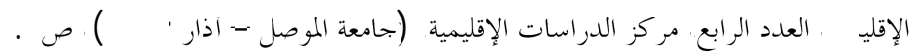

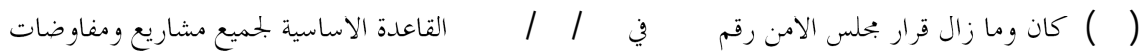

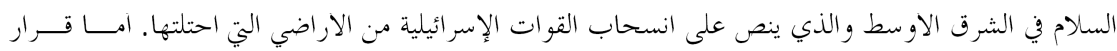

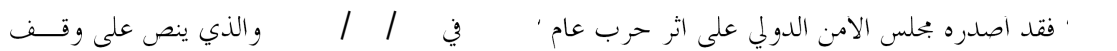

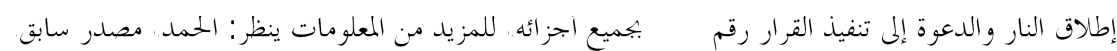

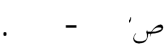

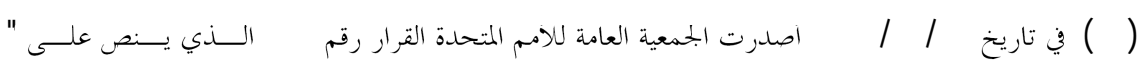

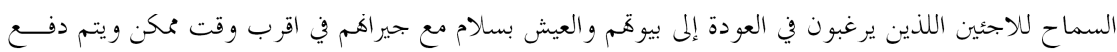

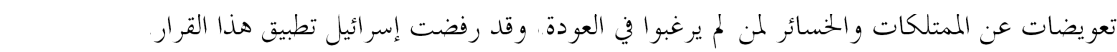

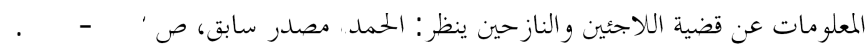

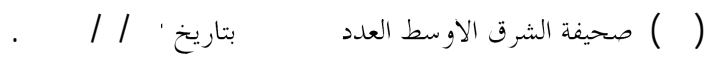


در اسات إقليمية 7 (10)

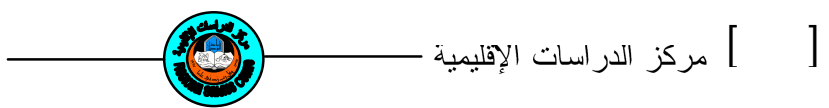

(سَع) عبد اللّ العمادي، "المبادرة السعودية ومحاولة التطبيع في الخليج العربي"، بحث منشور على الموقع:

http://www.aljazeera.net

$$
\begin{aligned}
& \text { (ع) العلاف، مصدر سابق، صگr) } \\
& \text { (ع) كورز، مصدر سابق. } \\
& \text { (ع7) العلاف، مصدر سابق، صَّا. } \\
& \text { (EV) } \\
& \text { (CN) الشرق الاوسط، CNN، بالعربية على الموقع: }
\end{aligned}
$$

http://Arabic.cnn.com/2007/middle east/3/2

(ع) (المصدر نفسه. (2) (2) 